\title{
AS ATUAIS POLÍTICAS PÚBLICAS DE AVALIAÇÃO PARA A EDUCAÇÃO SUPERIOR E OS IMPACTOS NA CONFIGURAÇÃO DO TRABALHO DOCENTE
}

\author{
Elisa Antonia Ribeiro*
}

Recebido: 22 out. 2010

Aprovado: 06 mar. 2012

Resumo: Neste artigo discorre-se, sucintamente, sobre a crise do capital e a implementação das políticas neoliberais cuja intencionalidade foi a de conter a crise de rentabilidade. Tendo essas questões como pano de fundo, situam-se as políticas de avaliação da educação superior formuladas no governo FHC e atualiza o debate sobre a avaliação na gestão do presidente Lula. Destaca os aspectos gerais da Lei n.10.861/2004 que criou o atual Sistema Nacional de Avaliação da Educação Superior (SINAES) e reflete sobre qual a tendência dessa política, a partir da edição, pelo governo, em 2008, dos índices, Conceito Preliminar de Curso (CPC) e Índice Geral dos Cursos (IGC). Estes índices podem provavelmente alterar a lógica formativa do SINAES, gerando nas IES uma certa "descrença" com a proposta inicial do SINAES. Na parte final, expõem, com base em uma pesquisa empírica realizada em duas IES, quais são os aspectos da docência universitária que estão sendo modificados e/ou ressignificados para atender às demandas do Estado Avaliador em conformidade com o modo de produção e a atual política de avaliação. Os resultados mostraram que alguns aspectos relativos à docência estão sendo alterados após o resultado da autoavaliação institucional, por exemplo, na IES privada, os aspectos relativos ao relacionamento professor X aluno, e, na IES pública, o da condução da aula.

Palavras-chave: Políticas de avaliação. SINAES. Trabalho docente.

\section{THE CURRENT HIGHER EDUCATION EVALUATION PUBLIC POLICY AND THE IMPACT ON THE TEACHING PROFESSION}

Abstract: This article briefly discusses the crisis of capital and the implementation of neoliberal policies whose intent was to contain the crisis of profitability. Taking these issues as background, we discuss the higher education evaluation policy developed during Cardoso's presidency, updating the debate on evaluation which occurred during the administration of President Lula. It highlights the general aspects of Law n.10.861/2004 that created the current System of National Higher Education Evaluation (SINAES) and reflects on the tendency of this policy, considering the creation by the government in 2008, of the Preliminary Program Grade, known as CPC, and the General Program Index, known as IGC. These indices are likely to change the formative logic of SINAES, generating in higher education institutions a "disbelief" with regard to the original proposal of SINAES. In the final part, the article presents, based on empirical research carried out in two HEIs, aspects of university teaching that are being modified and / or re-signified to meet the demands of the Evaluative State in accordance with the mode of production and the current evaluation policy. The results showed that some aspects of teaching are being changed after the results of institutional self-evaluation, namely, in private HEIs, the aspects relating to student- teacher relations, and, in public HEIs, the way of teaching a class.

Key words: Policy evaluation. SINAES. Teaching. 


\section{INTRODUÇÃO}

Este artigo se propõe a discutir as modificações produzidas pelo capital em resposta ao enfrentamento da última crise e, por consequência, os seus desdobramentos nas políticas públicas para a educação superior formuladas no governo Fernando Henrique Cardoso (doravante FHC), onde tiveram sua origem, e no atual governo do presidente Luis Inácio Lula da Silva (doravante Lula), as quais guardam certa continuidade, especificamente, no campo da avaliação da educação superior. O artigo mostra, ainda, de que forma os resultados da autoavaliação institucional (AAI), obrigatória para todas as Instituições Federais de Ensino, a partir da Lei n. 10.861 de 14 de abril de 2004 que criou o Sistema Nacional de Avaliação da Educação Superior (SINAES), são incorporados pelos docentes e quais os aspectos do trabalho docente na sala de aula estão sendo reconfigurados e/ou alterados.

O pano de fundo que orienta a presente discussão é a reflexão acerca da crise do Estado de Bem-Estar e o surgimento do Estado Mínimo que inaugurou um novo modelo de sociedade estabelecida nos princípios neoliberais. Os dados empíricos utilizados para a compreensão dos impactos da AAI na reconfiguração do trabalho docente foram o resultado de uma pesquisa sobre o processo e as práticas de autoavaliação institucional desenvolvidas em duas Instituições de Ensino Superior (IES).

Na primeira seção, discorremos, sucintamente, sobre crise do capital e a implementação das políticas neoliberais ${ }^{1}$ cuja intencionalidade foi a de conter a crise sustentada pela baixa rentabilidade do capital. Em seguida, situamos as políticas de avaliação da educação superior formuladas no governo FHC, e atualizamos o debate na gestão do presidente Lula, mostrando os aspectos gerais do SINAES, bem como a tendência da proposta no decorrer dos últimos dois anos. Por último, apresentamos os resultados da pesquisa realizada nas IES sobre quais os aspectos da docência universitária que estão sendo ressignificados para atender às demandas do Estado Avaliador em conformidade com atual modo de produção.

Com o objetivo de organizar o pensamento lógico, elegemos as seguintes questões como estruturantes desse artigo: de que forma se processou o processo de reconfiguração do atual modelo de produção? Quais são as forças aliadas ao capital que vêm influenciando a formulação das políticas regulatórias para a educação superior a partir dos anos 1990? Como o SINAES, enquanto

1 Para adensamento sobre o impacto da concepção de Estado Mínimo nas políticas educacionais no Brasil, podem ser citados os trabalhos de Chauí (2001), Gentili (1995, 2001), Gentili; Silva (1994), Silva Jr. (2005), Silva; Gentili (1996). 
política pública de avaliação para a educação superior, imposta às IES, afeta o campo do trabalho docente? Qual a contribuição dos resultados da AAI na prática docente?

\section{CRISE MUNDIAL DO CAPITAL E A FORMULAÇÃO DO IDEÁRIO NEOLIBERAL}

Nas últimas três décadas do século passado, o modelo de Estado de BemEstar Social passou por um intenso processo de reestruturação econômica e de reajustamento social e político resultante da "crise mundial”. Esta crise foi explicada por Harvey (2004, p.140) como sendo impulsionada pela:

profunda recessão de 1973, exacerbada pelo choque do petróleo, evidentemente retirou o mundo capitalista do sufocante torpor da "estagflação" (estagnação da produção de bens e alta inflação dos preços) e pôs em movimento um conjunto de processos que solaparam o compromisso fordista. Em conseqüência, as décadas de 1970 e 1980 foram um conturbado período de reestruturação econômica e de reajustamento social e político.

Os impactos dessa crise do capital, considerada estrutural, tiveram interferência direta na reorganização das funções e prioridades do Estado, com reflexos imediatos no papel e na finalidade da educação, principalmente, a superior, mediante a redefinição da gestão acadêmica e na reconfiguração do trabalho docente.

A alternativa do capital para o enfrentamento da crise foi reinventar o padrão de acumulação, promovendo o ajuste na forma e na mentalidade da produção. Ou seja, de forma estratégica o capital inventou um novo regime de produção econômica, associado a um sistema de regulamentação política e social bem distinta, denominado por Harvey (2004) de "acumulação flexível". Os princípios ideológicos desse modelo de acumulação flexível estabeleciam: a rapidez de mudança, a fluidez e a incerteza, interconectados em todos os espaços da vida social.

De forma específica, no campo da reestruturação econômica, assistiu-se à modificação no modelo de produção e, por consequência, nos padrões de consumo da sociedade. Os resultados foram: "transformações radicais nas formas de produção da vida humana em todas as suas dimensões, em razão da própria racionalidade histórica da formação econômico-social contemporânea” (SILVA JUNIOR; FERRETTI, 2004, p. 27). 
Além de Harvey (2004), Chesnais (1996) tratou conceitualmente a essa nova forma de reestruturação do capital por mundialização do capital -, que influenciou e provocou a recomposição das funções do Estado. O papel anterior do Estado, o qual era o de atender às questões de cunho social, como saúde, educação e habitação, orientadas para o bem-estar da população, transformouse em políticas de liberalização, desregulamentação e privatização dos setores ligados ao social.

Assim, o novo padrão capitalista de produção ocasionou o reajustamento social e político mediante a alteração substancial da forma de organização e atuação do Estado de Bem-Estar Social ou intervencionista, denominado também Estado-Providência pelo autor Santos (2006). Para este autor, o EstadoProvidência representou o pacto social entre o trabalho e o capital, originado no início do século XX, impulsionado pelo término da II Guerra Mundial e pelas propostas contratadas no New Deal ${ }^{2}$. Este modelo esteve ligado aos Estados cujas políticas sociais e econômicas voltavam-se para equalizar a produção da desigualdade, segregação e exclusão da população.

O modelo de Estado de Bem-Estar Social floresceu e expandiu associado ao padrão de produção capitalista fordista; no entanto, com a crise do petróleo, as bases desse binômio foram questionadas, uma vez que foram incapazes de garantir a restauração da lucratividade para o processo de acumulação capitalista. A fim de recompor o seu poder hegemônico, o capital pôs em movimento um conjunto de processos que solaparam o compromisso do modelo Estado de Bem- Estar Social/Fordismo.

Diante dos sinais de esgotamento do Estado de Bem-Estar Social, o campo para a promoção da alteração do papel do Estado floresceu com a propagação das lições defendidas na London School of Economics e na Escola de Chicago. A incapacidade do Estado de Bem-Estar Social de continuar a promover políticas equalizadoras completou os motivos precedentes para que o capital conduzisse as modificações, no campo político, necessárias para a implementação do ideário neoliberal. Os teóricos dessa corrente são contrários à concepção do Estado-social e apregoam que o Estado tem apenas uma função - garantir, através de seu aparato, o livre mercado. Estas ideias já eram defendidas pelo liberalismo clássico do século XVII, mas o Estado neoliberal tem um diferencial: o descompromisso com as questões sociais, afetando a saúde, a educação, a infraestrutura, a segurança e a política previdenciária da coletividade, ou seja, agravando ainda mais a desigualdade entre as nações e entre os indivíduos.

2 Refere-se ao conjunto de medidas em forma de programas implementados nos EUA durante o Governo do Presidente Franklin Delano Roosevelt (1933-1937), com o intuito de sanear a economia norte-americana e dar assistência aos lesados pela grande depressão. 
O autor Anderson (1995) afirmou que a implementação do ideário neoliberal ocorreu de forma sistemática e em nível mundial, variando somente no que tange à intensidade do seu poder de destruição do tecido social. No Brasil ${ }^{3}$, teve início nos governos de Collor de Mello (Março/1990-Dez/1992) e de Itamar Franco (Dez/1992-Jan/1995), mas se efetivou concretamente com o governo de Fernando Henrique Cardoso (Jan/1995-Dez/2002) e, contrariando as expectativas, o governo de Luiz Inácio Lula da Silva (Jan/2003-Dez/2010) tem produzido algumas políticas de cunho social em resgate à função do Estado-providência; no entanto, os preceitos dessa doutrina neoliberal ainda são mantidos.

\section{AS POLÍTICAS DE AVALIAÇÃO PARA EDUCAÇÃO SUPERIOR NOS GOVERNOS FHC}

Nos países periféricos, como o Brasil, a reforma do Estado nos anos de 1990, as muitas políticas educacionais e os ajustes estruturais impostos pelos últimos governos ditaram, sob a égide dos organismos internacionais - Banco Interamericano e Fundo Monetário -, os objetivos e o formato das mudanças nas IES. A adesão do país ao cânone neoliberal trouxe às IES dois desdobramentos graves: a implantação de uma lógica de funcionamento empresarial (associada à privatização da educação superior e à expansão do mercado educacional) e o processo de diferenciação institucional das IES.

O governo do presidente FHC veio consolidar a política neoliberal e a hegemonia do pensamento privatista no campo da educação e em outras esferas. A esfera pública foi restringida por meio de uma nova regulamentação que possibilitou a expansão da esfera privada devido à Reforma Gerencial do Estado, liderada pelo ministro da Administração Pública, Luiz Carlos Bresser Pereira, como uma das primeiras medidas do então presidente. O projeto de governo de FHC estava centrado doutrinariamente nos pressupostos da desregulamentação do mercado, abertura comercial e, especialmente, financeira e na redução do tamanho do papel do Estado no trato com as questões sociais. Na visão de Silva Junior (2005), a política de reforma desse governo redesenhou o Estado e a sociedade civil, prospectando para o primeiro a condição de Estado enxuto e forte, sob o domínio de uma ideologia gerencial e gerando um novo paradigma de políticas públicas cuja oferta se deu no âmbito da sociedade civil.

3 Em referência ao artigo de Oliveira (1995), o "neoliberalismo à brasileira" possui em sua essência a velha e clássica concepção de liberalismo existente que se difere do liberalismo europeu. O liberalismo brasileiro, assim como nos países da América Latina, traz em si simbolismos de um autoritarismo ditatorial. Especialmente no Brasil, o esperado pacto social pelo desenvolvimento é, hoje, um pálido simulacro do projeto que constava na agenda dos governos eleitos pelo povo. 
No campo da educação superior, a política constituída restabeleceu a tendência de expansão via iniciativa privada. Nesse sentido, o governo FHC manteve e, em certa medida, acentuou as políticas de reforma do Estado que vinham sendo incrementadas desde o início dos anos 1980. Como consequência, a reforma do Estado promovida pelo governo materializou-se na instituição de uma política de capitalismo concorrencial, voltada para a equalização das condições de concorrência do setor privado (CUNHA, 2003).

As medidas adotadas pelo Estado Neoliberal objetivaram gerar as alterações necessárias para o avanço das reformas educacionais, no campo da educação superior, notadamente, via a publicação contínua e abusiva de diversas normas: leis, medidas provisórias, decretos, medidas administrativas e políticas. Essa ação implicou novos contornos para as universidades e a postulação de uma lógica de avaliação afinada com os princípios do Estado Avaliador. Na compreensão de Neave (1990, p. 8), o Estado Avaliador consiste

en una racionalización y una redistribución general de funciones entre el centro y la periferia, de manera tal que el centro conserva el control estratégico global, por medio de palancas políticas menores en número, pero más precisas, constituidas por la asignación de misiones, la definición de metas para el sistema y la operación de criterios relativos a la calidad del producto [...]. El Estado evaluador surge del planteamiento de que no se cambia el mundo por decreto.

O conceito de Estado Avaliador expressa o modelo de gestão pública orientada para resultados. Nesse modelo, o foco do controle passa dos processos para os resultados, substitui-se o controle formal pelo controle dos resultados, por meio de avaliações finalísticas, de resultados.

Nesse contexto, justificou, ainda, a centralidade da avaliação da educação superior a incorporação do discurso do poder que a avaliação tem de induzir modificações nas instituições de ensino com a finalidade de provocar mais competitividade. As agências supranacionais também apontaram a avaliação como vetor de melhoria da qualidade da educação para os países periféricos.

De tal modo, uma das primeiras ações legais acerca do que e como deveria ser a avaliação da educação superior no governo de FHC foi a promulgada Lei n. 9.131/954, de criação do Exame Nacional de Curso (ENC), conhecido popularmente por Provão. Com essa lei estava sendo colocado em cena um processo de avaliação da educação superior calcado em pressupostos de uma avaliação classificatória, imediatista, finalística, sem a participação dos atores

4 Altera dispositivos da Lei no 4.024, de 20 de dezembro de 1961. 
acadêmicos e totalmente realizada externamente à Universidade (CARNEIRO; NOVAES, 2008). Posteriormente, "foram sendo editadas medidas que incluíram no "soi-disant" sistema de avaliação da educação superior construído durante o governo FHC, o Censo de Educação Superior e a Avaliação das Condições de Ensino (ACE)”. Este procedimento constituiu-se de visitas in loco às IES, realizadas por Comissões de Especialistas, por área do conhecimento, designadas pelo MEC, a fim de verificar os aspectos referentes à organização didático-pedagógica dos cursos, corpo social e infraestrutura; todavia, o Provão permaneceu no centro desse sistema (CARNEIRO; NOVAES, 2008, p. 719).

Destarte estava sendo montado um esquema de avaliação orientado exclusivamente para resultados e com forte apelo ideológico, pois concedia à sociedade o poder de escolha sobre os produtos educacionais oferecidos, à semelhança do que acontece no mercado. Nesse esquema, estava determinado que a característica mais marcante do projeto educacional "é o destaque para o papel econômico da educação, como "base do novo estilo de desenvolvimento", cujo dinamismo e sustentação provêm de fora dela mesma - do progresso científico e tecnológico" (CUNHA, 2003, p. 38-39). Essa hipervalorização do caráter público da avaliação e seus efeitos nos âmbitos de interesse público, a partir dos anos 1990, caracterizou, na expressão de Dias Sobrinho (2003, p. 98), a "década da avaliação", resultante da substancial alteração do modo de organizar os processos produtivos. Essa subsunção tornou-se mais acentuada na segunda metade dos anos noventa, época em que o Brasil seguia a tendência internacional marcada por um forte movimento de avaliação da educação superior. "Como as empresas, as instituições educativas devem agora submeter-se aos critérios economicistas e gerenciais das empresas" (DIAS SOBRINHO, 2004, p. 708).

O sistema de avaliação instituído privilegiou o ensino de graduação, articulando-se fortemente à política deliberada de expansão do ensino superior que foi praticada no país. Segundo Morosini e Franco (2002, p. 5):

a presença do estado avaliador (NEAVE, 1991) no Brasil é tão forte que Cury (2000) afirma que existe um Sistema Nacional de Avaliação antes de um Sistema Nacional de Educação. O pressuposto é o de que a homogeneização, a coerência e o afinamento do sistema de educação resultam do sistema de avaliação.

De tal modo, o quadro de avaliação da educação superior, no mandato de FHC, configurou-se por meio de vários dispositivos regulatórios externos, em que predominou o resultado do Provão sobre os demais mecanismos legalmente 
instituídos e ilegalmente descumpridos. Assistiu-se à desconsideração à identidade das IES, a sua inserção e atuação na sociedade, e menos, ainda, o respeito ao seu projeto institucional. Os resultados do Provão provocaram, inevitavelmente, o estabelecimento de ranking interinstitucional, criando-se situações embaraçosas para as instituições e seus alunos, caso o desempenho não fosse favorável. Foi assim que o governo FHC encerrou o mandato deixando para seu sucessor uma concepção de educação superior balizada na visão mercantil e pragmatista, acendendo a forte expansão da educação superior privada e um modelo de avaliação com foco exclusivo no curso.

\section{AS POLÍTICAS DE AVALIAÇÃO PARA EDUCAÇÃO SUPERIOR NOS GOVERNOS LULA}

O início do governo do presidente Lula foi marcado pelo tom da condução de um processo de revisão das políticas de regulação da educação superior. Nas primeiras movimentações do governo houve a tentativa da incorporação de novos elementos à forma de governar: abertura à participação da comunidade acadêmica nas discussões, perspectiva de elaboração de um sistema nacional de avaliação e extinção do Provão; contudo, a caminho do término do mandado, no que se refere ao empenho em desenvolver uma política para a educação superior, constata-se a manutenção de certa linha de continuidade das práticas avaliativas com foco no resultado e na publicação dos resultados.

A expectativa da comunidade acadêmica era pela formulação de uma proposta de avaliação para a educação superior balizada na concepção formativa e pedagógica de avaliação, oportunizando "olhar" a universidade em todas as suas dimensões. Em princípio, houve a disposição ao acolhimento dessa expectativa quando da institucionalização da Comissão Especial de Avaliação da Educação Superior (CEA) ${ }^{5}$, com a finalidade de discutir a criação de um novo sistema de avaliação do ensino superior. Esta Comissão estava filiada a uma concepção de avaliação cuja perspectiva era a de promover a ruptura ao modelo implementado durante o mandato do presidente FHC.

Portanto, das discussões do governo com a sociedade, notadamente com o mundo acadêmico, e não mais tão ligado ao mundo produtivo, surgiu, após embate de forças ${ }^{6}$, em abril de 2004, a Lei ${ }^{\circ} 10.861$, que criou o Sistema Nacional de Avaliação da Educação Superior (SINAES). O objetivo proposto

5 Esta Comissão foi designada pelas Portarias MEC/SESu nº. 11 de 28 de abril de 2003 e nº 19 de 27 de maio de 2003.

6 Para compreensão dos bastidores da formulação até a aprovação do projeto final, conferir Barreyro e Rothen (2006). 
para este novo modelo é o de avaliar os aspectos concernentes ao ensino, à pesquisa, à extensão, além disso, à responsabilidade social, ao desempenho dos alunos, e aspectos da gestão da instituição, do corpo docente e das instalações (SINAES, 2007). Os resultados das avaliações deverão ser utilizados pelas IES para orientação da sua eficácia institucional, efetividade acadêmica e social, pelos órgãos governamentais para encaminhamento de políticas públicas e, pelo público em geral, para a orientação de suas decisões quanto à "qualidade" dos cursos e das instituições. Mais especificamente, os resultados da avaliação institucional deverão subsidiar os processos de regulação do sistema de educação superior, seja no credenciamento de IES, seja na autorização, reconhecimento e renovação de reconhecimento de cursos.

A proposta visa assegurar uma coerência, tanto conceitual quanto procedimental, buscando garantir a articulação da natureza formativa, voltada para a perspectiva de autoconhecimento das instituições com as funções de natureza regulatória próprias do Estado.

Com essa nova sistematização, ficam claras algumas configurações da ação do Estado na educação superior: a separação entre avaliação e regulação; a definição da avaliação institucional como foco; a instauração de um processo de avaliação formativo; a interface que deve ser estabelecida entre avaliação e regulação.

O SINAES, com tais características, foi instituído como uma política de avaliação institucional, inédita no país; todavia, nos primeiros meses do ano de 2008, a comunidade acadêmica, subitamente, tomou conhecimento, via mídia, do prenúncio de mudanças na filosofia do SINAES, indicando que o governo acenaria para modificações no papel do Estado quanto aos processos de avaliação da educação superior.

Esta nova fase governamental apresentou a instalação de dois novos indicadores no contexto da educação superior brasileira, as mudanças estão em curso e não há perspectiva de que haverá alteração de rota. De fato, o SINAES está dando sinais de esgotamento, e o não cumprimento do estabelecido, contrariando a expectativa de que o SINAES teria papel central na regulação, com a utilização dos resultados da avaliação institucional, tendo como centro a AAI, conduzida pela Comissão Própria de Avaliação (CPA), mediante a participação da comunidade.

A situação atual é a de que a avaliação da educação superior é regulada pelos dois novos índices criados: o Conceito Preliminar de Curso (CPC) e o Índice Geral de Cursos da Instituição de Educação Superior (IGC). Com isso, iniciou-se o processo de alteração da concepção de sistema do 
SINAES, porquanto houve a "desconsideração e/ou minimização de dois instrumentos do SINAES: a) a avaliação institucional e a avaliação de cursos pela utilização do IGC, b) a indução do ranqueamento das Instituições, levando em conta os resultados desse índice, c) o sobre-dimensionamento dos resultados do exame ENADE para compor esses índices". (ROTHEN; BARREYRO, 2009, p.745).

No período do governo FHC, o processo desenvolvido para a avaliação da educação superior esteve vinculado ao Estado Avaliador com foco no curso e não na instituição. Com o governo Lula, de seu início até 2007, a avaliação foi tema recorrente da agenda governamental como proposta de superação do viés ranqueador do Provão, para uma proposta cujo sentido seria o de respeito à identidade institucional e ao núcleo operacional - a avaliação institucional - momento em que foi instituído o SINAES. Infelizmente, em 2008, "ao que parece, o súbito aparecimento do CPC e do IGC não mostra apenas questões técnicas, mas parece responder a lógicas e propostas diferentes da estabelecida no primeiro governo Lula, quando da proposta e aprovação do SINAES” (BARREYRO, 2008, p. 867).

Contudo, até o momento, não se pode negar que a avaliação trouxe impacto ao contexto das IES, o que foi confirmado tanto nas análises estatísticas, como nos pareceres das comissões de avaliação in loco. Esse impacto pode ser observado, inclusive, pela força de sua função supervisora e reguladora, na proporção em que induz as instituições a acatar um dado padrão de qualidade para obter conceitos positivos e se manter competindo no mercado, o que foi evidenciado a partir do processo de expansão de instituições.

Destacamos, na próxima seção, alguns resultados de uma pesquisa ampla e complexa, realizada em duas IES, sobre o processo e as práticas da AAI, de forma particular, sobre o item a incorporação e os impactos dos resultados no trabalho docente.

\section{A INCORPORAÇÃO DOS RESULTADOS DA AUTOAVALIAÇÃO INSTITUCIONAL NA PRÁTICA DOCENTE}

Os resultados a seguir foram obtidos da pesquisa desenvolvida no doutorado (RIBEIRO, 2010). Dentre outros aspectos investigados, nesse artigo destacamos os resultados, nomeadamente, da seguinte questão: Quais são os aspectos da atuação docente que estão sendo ressignificados, alterados e/ou modificados a partir da proposta de AAI determinada pelo SINAES? 
A investigação foi realizada tendo como referência dois universos: uma instituição pública da rede federal e um centro universitário privado, localizados no Estado de Minas Gerais. Os dados foram coletados no ano de 2009 e consolidados em 2010, utilizando como método o estudo de caso e a técnica análise de conteúdo; no levantamento dos dados, utilizamos o questionário com 11 questões abertas. O sujeito da pesquisa, nesse item sobre os impactos do resultado da AAI na prática docente, foi o segmento docente. A amostragem constituiu-se de $65 \%$ e $55 \%$ do total de docentes da IES privada e pública, respectivamente. Na transcrição das respostas empregamos a seguinte identificação7: a sigla DP, designativa de docente privada e, logo em seguida, número de identificação para cada docente - de 01 a 56 - e o número de anos do professor na docência universitária. Para os docentes da IES pública, empregamos a sigla DF - docente federal - e, logo em seguida, número de identificação - de 01 a 10. No caso dos docentes da IES pública, o tempo de docência universitária não foi computado, pois a maioria dos professores tem o mesmo tempo de experiência, média de 04 anos, tempo que corresponde à criação do $1^{\circ}$ curso superior na Instituição ${ }^{8}$ pesquisada.

Os dados utilizados com a finalidade de verificar a efetividade da repercussão dos resultados da avaliação docente foram analisados a partir das seguintes questões do questionário: a) quais as atitudes desencadeadas pelo professor após o recebimento do relatório com os resultados da avaliação? b) Quais as possíveis contribuições que os resultados da AAI trazem para a atuação docente?

A partir do conteúdo dos depoimentos dos docentes das duas IES, verificamos que os docentes tiveram as seguintes atitudes após o recebimento dos resultados da avaliação: a) refletir sobre o resultado; b) refletir sobre o resultado e buscar modificação na atuação; c) discutir com os alunos o resultado e buscar modificações na atuação; d) interessar-se somente pelo resultado positivo, ignorando o negativo. Não identificamos qualquer depoimento que indicasse uma postura de negação do docente após receber o resultado. Ou seja, o professor, diante do resultado, sempre escolhe tomar uma decisão.

O conjunto dos depoimentos dos docentes da IES privada permitiu levantar um percentual de $48 \%$ de respostas evidenciando que para esses docentes está explícito o fundamento de qualquer proposta AAI balizada na concepção pedagógica e formativa: o movimento dialético - reflexão-ação-reflexão. A avaliação com sentido formativo induz os participantes à ação e ao movimento,

7 Exemplo: DP/03-7anos e DF/08.

8 A instituição tem tradição na oferta de curso técnicos de nível médio e a maioria dos professores conta com 16 anos de efetivo exercício na docência nesse nível. 
promovendo uma atitude tanto de reflexão sobre o desempenho, quanto de "vontade" para dar início à outra forma de se pensar e atuar na realidade. Essa compreensão a propósito da finalidade da avaliação - a tomada de decisão - está nos depoimentos que selecionamos e reproduzimos a seguir:

De posse do resultado, estudo com cuidado cada item e, quando vejo necessidade, converso com os alunos buscando encontrar caminhos para um aperfeiçoamento (DP/3-6anos).

Nas duas primeiras avaliações fiquei muito feliz, nessa última, fiquei mais preocupado, e já mudei meu procedimento de dar aula e de comunicação com os alunos (DP/6-2anos).

O resultado me permite uma reavaliação da minha postura e alteração necessária, tanto pessoal quanto profissional, ignorando os resultados em alguns momentos e fazendo ponderações sobre as informações para melhorar (DP/9-11 anos).

Os resultados me possibilitam identificar os pontos fortes e fracos da minha conduta, fazem com que eu possa reorientar as minhas ações acadêmicas; desencadeando um processo pedagógico de construção e aprendizado acadêmico, a partir da auto-avaliação (DP/13-8 anos).

Diante dos resultados procuro aprofundar frente as necessidades/problemas levantados, agindo de forma pró-ativa (DP/2- 6anos).

Procuro utilizar os resultados, ainda que não concorde com o resultado em primeira análise, para investigar meu comportamento em sala de aula. Muitas vezes, percebo que o resultado não era tão distante da realidade (DP/23-9 anos).

O discurso da maioria dos docentes da IES pública contém elementos indicativos da presença da atitude de refletir sobre os resultados da avaliação para posterior implementação de melhoria da ação pedagógica. Por exemplo: "de posse dos resultados verifico onde possivelmente errei, se estes erros forem representativos, traço estratégias de melhoria para as falhas e de reforço para os acertos" (DF/04). Desse conjunto de respostas dos docentes, levantamos uma única resposta indicando a não utilização dos resultados da avaliação e, com isso, observamos uma única postura docente descaracterizando a finalidade da avaliação qual seja a tomada de decisão.

Podemos afirmar que para os docentes da IES pública os resultados da avaliação têm um impacto psicológico menor, por isso, é menos evidente e imediata a alteração da atuação do professor. Eles também recebem o resultado com mais tranquilidade, menos ansiedade e sofrimento, pois a avaliação do 
discente, nesse contexto, tem peso menor; já para os docentes da IES privada, esse peso é maior, uma vez que estão permanentemente submetidos à máxima do ideal neoliberal: resultados.

Ainda sobre a incorporação dos resultados da avaliação docente na prática, perguntamos aos docentes: "a autoavaliação institucional trouxe alguma contribuição para a sua atuação em sala de aula? O resultado observado foi que 95\% dos docentes das IES responderam afirmativamente que "sim", juntamente com as variantes “certamente”, “com toda certeza”, "muito”. O alto índice de respostas positivas verificado confirma o pressuposto da pesquisa desenvolvida, isto é, de que alguns aspectos da atuação do docente universitário estão sendo ressignificados, modificados e/ou repensados em função dos resultados da avaliação e das atuais políticas de avaliação para a educação superior em curso desde o início da década de 1990.

Contrárias à afirmação sobre a legitimidade da contribuição da avaliação, levantamos duas respostas apontando que os resultados da avaliação contribuíram pouco para determinar qualquer modificação na atuação do docente. Vejamos as respostas: "os resultados trouxeram pouca modificação, talvez por ter sido bem avaliado", (DP/7- 9 anos) e "os resultados impactaram muito pouco na alteração das minhas aulas” (DP/12-8 anos). De um total de 56 respostas, somente duas foram totalmente opostas à maioria do grupo, pois afirmaram que os resultados da avaliação docente não impactaram na atuação docente. Vejamos as respostas: "até o momento, os resultados não modificaram a minha atuação" (DP/17-01 ano) e “ainda não” (DF/10).

Corroborando o achado da pesquisa de que os resultados da avaliação discente têm impacto na atuação do docente, selecionamos algumas respostas elaboradas pelos docentes da IES privada:

Rever o que não correspondeu aos nossos objetivos e, por outro lado, considerar aqueles pontos que foram válidos (DP/1-8 anos).

Perceber melhor o que posso melhorar e os meus pontos fortes também como docente (DP/2- 5 anos).

Ter uma visão mais crítica de minha atuação (DP/5-4 anos).

Traçar uma direção, um norte a ser "melhorado" no próximo semestre (DP/1608 meses).

Construir um referencial daquilo que devo melhorar (DP/20-13 anos).

Até o presente momento só benefícios, pois consigo realmente me avaliar (DP/226 anos). 
Refletir sobre os tópicos nos quais fui bem avaliado e nas partes em que fui criticado. Acredito que a autoavaliação serviu como alerta do que não fazer e como norte do que melhorar (DP/23-9 anos).

Selecionamos, também, algumas respostas que mostram, de foram explícita, quais são os aspectos da sala de aula que estão sendo ressignificados, modificados e/ou repensados em função do impacto dos resultados da avaliação docente:

Aprendi a ter mais paciência com os alunos, entender que muitos não têm condições, pelo menos inicialmente, de acompanhar o raciocínio (DP/11-6 anos).

Proporcionou não só o autoconhecimento institucional, o que é de grande importância para mim, bem como serviu para constituir o momento ideal para eu rever e planejar estratégias para que, cada dia mais, a nossa Instituição seja uma referência em qualidade de ensino (DP/13-8 anos).

Contribuiu muito com a qualidade de muitas aulas. Permitiu-me repensar as aulas e alterar métodos, procedimentos, enfoques, diretrizes (DP/26-9 anos).

Possibilitou gerar informações para novo planejamento, definição de critérios (DP/29-14 anos).

Com o conhecimento das informações da autoavaliação pude adequar as minhas técnicas pedagógicas (DP/33-12 anos).

O conjunto das respostas dos docentes da IES pública, também, aponta o impacto do resultado da AAI na atuação do professor e indica quais são os aspectos da sala de aula relativos à atuação docente que estão sendo modificados:

Detectam-se pontos falhos na atuação docente, "ninguém é perfeito”, então procuro seguir as dicas, conselhos e tento fazer o meu trabalho da melhor maneira possível buscando sempre atingir os objetivos da instituição (DF/01).

Todos os professores após um longo tempo na carreira tendem a desenvolver vícios, como por exemplo, linguajar técnico mais complexo. Observar que alguns alunos reclamam de fatos como estes, me levaram a realizar modificações nas notas de aulas e maneira de desempenhar meu papel em sala de aula (DF/06).

Acho que toda avaliação é positiva e contribui para a melhoria da qualidade do ensino, pois revela as carências e norteia a instituição para a criação de condições para a melhoria do ensino aprendizagem. Isto, com certeza, reflete na atuação do professor, seja na sala de aula, seja na busca de maior qualificação (DF/02). Já fiz uso dos dados coletados para redirecionar questões didático-pedagógicas (DF/04). 
Os resultados ajudaram a refletir sobre os procedimentos empregados durante as aulas, indicação de bibliografia, atividades em grupo (DF/07).

A partir dos resultados podemos refletir sobre os pontos fracos e rever a condução das aulas, buscando verificar quais os itens que precisam ser melhorados, por exemplo, mais exercícios de revisão, adequar a linguagem ao nível da turma (DF/09).

Confirmamos que os resultados da AAI trazem contribuições tanto para os docentes com mais anos de experiências na docência, quanto para os que estão iniciando a carreira. Com isso, reforça-se a ideia de que o papel de divulgação, sensibilização e socialização dos resultados colaboram para a criação do vínculo entre o resultado da avaliação e a consequente tomada de decisão pelos envolvidos.

Constatamos que tanto os docentes da IES privada quanto da pública percebem que os resultados da AAI têm contribuído para planejar, replanejar e/ou repensar alguns aspectos da sala de aula relativos à atuação docente. $\mathrm{O}$ resultado produzido, nessa pesquisa, permite-nos afirmar que os docentes, ao vivenciarem um processo de avaliação significativo para o seu crescimento, refletirão na descoberta de uma melhor maneira de ensinar. No caso da IES privada, é preciso considerar um elemento que vem muito colado à melhoria da qualidade do desempenho do docente - a aceitação do trabalho desempenhado pelo docente conforme o que determinam os padrões da instituição -, esse elemento, na instituição pública, é mais distante, considerando o regime de estabilidade ao qual os docentes da IES pública estão submetidos.

Por fim, em um processo de avaliação docente, quanto mais os professores observam que o processo irá produzir satisfação, sugestões para melhoria das atividades desenvolvidas, alguma forma de incentivo à capacitação, eles tendem a se envolverem e aceitarem a proposta de avaliação e a utilizarem os resultados para refletir e agir sobre o seu trabalho.

\section{CONSIDERAÇÕES FINAIS}

É possível concluir que a política de avaliação para o ensino superior cujo contorno remonta às políticas macroeconômicas, no que tange à reestruturação da produção e à reforma do Estado, reconfiguraram o espaço administrativo e pedagógico das/nas IES. Nesse sentido, a política educacional ficou a reboque das decisões econômicas - nos moldes dos diagnósticos e recomendações dos organismos financeiros transnacionais - determinando o atual enfoque do modelo de avaliação da educação superior. 
A perspectiva trazida pelo SINAES, criado em 2004, de se estabelecer e se desenvolver de forma efetiva como um sistema de avaliação para a educação superior, orientado pelos princípios articulados - formador e regulador -, no início de 2008, teve sua finalidade descaracterizada ao promover o deslocamento da avaliação institucional - do centro do processo regulatório das IES para a utilização dos resultados dos dois índices criados, CPC e IGC - em atitude arbitrária do governo

Mesmo assim, ficou evidente que a AAI, na dimensão da avaliação docente, tem se firmado pela repercussão de que os resultados têm produzido ressignificações na gestão administrativa e acadêmica nas/das IES e nos/para os atores institucionais. A avaliação institucional está incorporada nos processos e nas práticas das IES, com viável possibilidade de já se poder falar em uma cultura avaliativa.

Consideramos pertinente o adensamento de pesquisas que busquem investigar aspectos relativos à docência universitária, contextualizados no seio das transformações que se processaram no mundo do trabalho, com o avanço do neoliberalismo e a expansão da globalização excludente. Essas futuras pesquisas são extremamente necessárias, dada a carência de investigações a esse respeito, para compreendermos as profundas mudanças que se operam no mundo do trabalho e no trabalho docente.

\section{REFERÊNCIAS}

ANDERSON, P. Balanço do neoliberalismo. In: SADER, E. ; GENTILI, P. (Orgs.). Pós-neoliberalismo: as políticas sociais e o Estado democrático. Rio de Janeiro: Paz e Terra, 1995. p. 09-23.

BARREYRO, G. B. De exames, rankings e mídia. Avaliação, Campinas; Sorocaba, v. 13, n. 3, p. 863-868, nov. 2008.

BARREYRO, G.; ROTHEN, J. C. SINAES contraditórios: considerações sobre a elaboração e implantação do Sistema Nacional de Avaliação da Educação Superior. Educação \& Sociedade, Campinas, v.27, n.96, p.955977, 2006.

BRASIL. Lei 9.131 de 24 de novembro de 1995. Altera dispositivos da Lei n. 4.024, de 20 de dezembro de 1961, e dá outras providências. Diário 
Oficial [da] República Federativa do Brasil, Brasília, D.F., v.133, n.225-A, p.19.257-8, 25 nov.1995. Seção 1.

BRASIL. Ministério da Educação. Secretaria de Educação Superior. Portaria SESU/MEC $\mathrm{n}^{\mathrm{o}} 11$, de 28 de abril de 2003. Com a finalidade de analisar, oferecer subsídios, fazer recomendações, propor critérios e estratégias para a reformulação dos processos e políticas de avaliação da Educação Superior e elaborar a revisão crítica dos seus instrumentos, metodologias e critérios utilizados. Diário Oficial [da] República Federativa do Brasil, Poder Executivo, Brasília, DF, 30 abr. 2003. Seção 2, p. 19.

BRASIL. Ministério da Educação. Secretaria de Educação Superior. Portaria SESU/MEC n ${ }^{\circ}$ 19, de 27 de maio de 2003. Com a finalidade de analisar, oferecer subsídios, fazer recomendações, propor critérios e estratégias para a reformulação dos processos e políticas de avaliação da Educação Superior e elaborar a revisão crítica dos seus instrumentos, metodologias e critérios utilizados. Diário Oficial [da] República Federativa do Brasil, Poder Executivo, Brasília, DF, maio 2003.

CARNEIRO, B. P. B.; NOVAES, I. L.. As comissões próprias de avaliação frente ao processo de regulação do ensino superior privado. Avaliação, Campinas; Sorocaba, v. 13, n. 3, p. 713-732, nov. 2008.

CHAUÍ, M. de S. Escritos sobre a Universidade. São Paulo: UNESP, 2001. CHESNAIS, F. A mundialização do capital. São Paulo: Xamã, 1996.

CUNHA, L. A. O ensino superior no octênio FHC. Educação \& Sociedade, Campinas, v. 24, n. 82, p. 37-61, 2003.

DIAS SOBRINHO, José. Avaliação: políticas educacionais e reformas da educação superior. São Paulo: Cortez, 2003.

- Avaliação ética e política em função da educação como direito público ou como mercadoria? Educação \& Sociedade, Campinas, v. 25, n. 88, p.703-725, 2004.

GENTILI, P. (Org.). Pedagogia da exclusão, crítica ao neoliberalismo em educação. Petrópolis, RJ: Vozes, 1995.

Universidades na penumbra: neoliberalismo e reestruturação universitária. São Paulo: Cortez, 2001. 
GENTILI, P. ; SILVA, T. T.(Org.). Neoliberalismo, qualidade total e educação. Petrópolis: Vozes, 1994.

HARVEY, David. Condição pós-moderna. 21. ed. Loyola: São Paulo, 2004. MOROSINI, M. C.; FRANCO, M. E. Políticas públicas de qualidade universitária e construção de espaços de participação. In: REUNIÃO ANUAL DA ANPED, 25, 2002, Caxambu, MG. Anais... Caxambu, MG, 2002.

NEAVE, Guy. La educación superior bajo la evaluación estatal: tendencias en Europa Occidental (1986-1988). Universidad Futura, México, v. 2, n. 5, 1990.

OLIVEIRA, F. de. Neoliberalismo à brasileira. In: SADER, E.; GENTILLI, P. Pós-neoliberalismo: as políticas sociais e o estado democrático. Rio de Janeiro: Paz e Terra, 1995. p. 24-28.

RIBEIRO, E. A. O processo de autoavaliação institucional proposto no Sistema Nacional de Avaliação da Educação Superior (SINAES) para as instituições públicas e privadas. 2010. 330f. Tese (doutorado) - Faculdade de Educação, Universidade Federal de Uberlândia, Uberlândia, 2010.

ROTHEN, J. C. ; BARREYRO, G. B. Avaliação, agências e especialistas: padrões oficiais de qualidade da educação superior. Ensaio: Aval. Pol. Públ. Educ., Rio de Janeiro, v. 17, n. 65, p. 729-752, 2009.

SANTOS, B. dos S. A gramática do tempo: para uma nova cultura política. São Paulo: Cortez, 2006.

SILVA JÚNIOR, J. dos R. Reforma do Estado no Brasil de FHC. São Paulo: Xamã, 2002.

\section{. Pragmatismo e populismo na Educação superior nos governos}

FHC e Lula. São Paulo: Xamã, 2005.

SILVA JUNIOR, J. dos R.; FERRETTI, C. J. O institucional, a organização e a cultura da escola. São Paulo: Xamã, 2004.

SILVA, T.T.; GENTILI, P. (Org.). Escola S. A.: quem ganha e quem perde no mercado educacional do neoliberalismo. Brasília, DF: CNTE, 1996.

SINAES - Sistema Nacional de Avaliação da Educação Superior: da concepção à regulamentação. 2007. 4.ed. ampl.- Brasília: INEP, 2007. 